\title{
The impact of COVID-19 on fertility plans in Italy, Germany, France, Spain and UK
}

\author{
Francesca Luppi ${ }^{1}$, Bruno Arpino ${ }^{2}$ and Alessandro Rosina ${ }^{3}$
}

\section{A revised version of this paper has been published in Demographic Research:}

Luppi, F. Arpino, B. Rosina, A. (2020). The impact of COVID-19 on fertility plans in Italy, Germany, France, Spain, and the United Kingdom. Demographic Research, 43, 1399-1412.

\begin{abstract}
This study offers an overview on changes in fertility plan during the COVID-19 crisis of a representative sample of the young population (18-34) in Italy, France, Germany, Spain and UK. Data were collected between March 27 and April 7, 2020. Our results show that fertility plans have been negatively revised in all countries, but not in the same way. In Germany and France fertility plans changed moderately, with many people still planning or postponing their decision to have a child during the 2020. In Italy, instead, the proportion of abandoners is much higher than in other countries, while comparatively it shows a lower proportion of those deciding to postpone their plans. Moreover, the demographic characteristics of the individuals seem to be associated with fertility plans in different ways across countries. In Italy, abandoners are common among individuals younger than 30 and those without a tertiary education. In Germany, abandoners are slightly more prevalent in the regions most affected by the COVID-19. In UK, fertility plans have been most frequently abandoned by individuals that expect the worse impact of the crisis on their future income. Finally, in France and Spain we did not observe a clear pattern for revision of fertility plans. These results suggest that different mechanisms are at work, due to the different economic, demographic and policy pre-crisis background and post-crisis prospects. Low-fertility contexts, in particular, appear to be more at risk of a fertility loss due to the crisis.
\end{abstract}

Keywords: covid-19, sars-cov-2, coronavirus, fertility plans, Italy, France, Germany, Spain, UK

${ }^{1}$ Università Cattolica del Sacro Cuore, Department of Statistics, Milan (Italy): francesca.luppi1@ unicatt.it

${ }^{2}$ University of Florence, Department of Statistics, Computer Science, Applications, Florence (Italy): bruno.arpino@unifi.it

${ }^{\frac{1}{3} \text { Università Cattolica del Sacro Cuore, Department of Statistics, Milan (Italy): alessandro.rosina@unicatt.it }}$ 


\section{Introduction}

Historically, economic crises have never been the preferred period for a couple to decide to have a baby. The millions of jobs lost in that circumstances, even when a couple is not directly affected, create a climate of great uncertainty, which depresses family projects (Adsera 2011, Goldstein et al. 2013, Matysiak et al. 2018). Therefore, we may expect the economic crisis due to the COVID-19 emergency to produce similar demographic outcomes. However, the fertility consequences of the crisis are not expected to be equally distributed across countries. Demographic, as well as economic, contextual features may support or further reduce individuals' pre-crisis fertility plans, by reducing (or not) the uncertainty derived by the negative economic trend (Adsera 2004, Kreyenfeld 2016, Caltabiano et al. 2017, Vignoli et al. 2019). In Europe, the climate of uncertainty caused by the COVID-19 pandemic might have been stressed by the still ongoing effect of the 2008 financial crisis, especially in Southern European countries where young people and women's employment indicators and fertility rates are the lowest (Matysiak et al. 2018). Additionally, the physical distancing required by the COVID-19 containment strategy imposed also restrictions to (physical) intergenerational support and this might affect more strongly fertility plans in those countries, such as Italy and Spain, where grandparental childcare is more intensive (Bordone et al, 2017; Price et al, 2018), also due to a lower availability of childcare services.

One of the distinctive characteristics of this economic crisis compared to others has been the clear perception of its huge impact on everyday life since the first days of the lockdown, but also on the constraints and opportunities of one's life choices. This means that, since the very beginning, people had the perception that things would have been changing, and that many of their future life plans needed to be revised accordingly. The aim of this study is to investigate the very first effect of the crisis on young people fertility plans compared to their pre-emergency plans, by comparing European countries among them (i.e. Italy, France, Germany, Spain and UK), and within them by comparing groups based on key socio-demographic characteristics, i.e. age, education, expectations on future income, residence in a region with high rate of COVID-19 cases.

\section{Data and method}

We use data from the survey "Rapporto Giovani” carried out by Istituto Giuseppe Toniolo and IPSOS. As far as we know, this is the first international survey on the COVID-19 impact on young generations fertility plans. It has been conducted between March 27-31, 2020 in Italy and April 2-7, 2020 in the other countries. Interviews were conducted using CAWI (Computer Assisted Web Interviewing) 
administered questionnaire on a representative sample - at the country level - of the young population (18-34 years old individuals; 6000 respondents overall). The individuals were chosen with a quota sampling technique: the representativeness is given by a significant set of different variables (gender, age, geographical origin, education, marital status, etc.) on which the quotas sample have been defined (more information available at: https://www.rapportogiovani.it/osservatorio/). Respondents answered to a question about their fertility plans at the beginning of the 2020 (before the start of the COVID-19 emergency). A further question on their fertility plans at the time of interview has been asked only to those who answered to have had some intention to conceive a child during the 2020. In particular, this last question asks: "Did the coronavirus emergency interfere in any way with this program?" with three possible answers: [1] "No, the program remains confirmed for 2020" ("still planners"); [2] "The program remains confirmed but I had to postpone it" ("postponers"); [3] "For now I have quitted the program ("abandoners")", from which we derived three possible groups of respondents.

We accounted for heterogeneities in fertility plans by gender, age (18-24, 25-29; 30-34), education (tertiary vs lower); expectations about future income and living in a region strongly hit by the COVID19 pandemic. More specifically, to account for the possible economic effect of the crisis, we considered the individuals' perceived uncertainty about their income. This is likely to be a projection of both their occupational (in)security and the indirect expected effect of the crisis on the economic system and labour market. The question is asked as "Thinking about your future, do you think the current coronavirus emergency will have a positive or negative impact on your (personal) income?" Answers were given on a scale from 1 (much negative) to 5 (much positive). The variable has been dichotomized, taking value 0 if the respondent is not expecting any effect or a positive effect (values 3, 4 and 5), and value 1 if the respondent is expecting negative income shocks (values 1 and 2). Finally, we considered a possible context effect due to living in a region which has been strongly affected by the diffusion of COVID-19 cases. Data have been obtained at the regional level (NUTS2 or NUTS1 according to the available level of aggregation in the survey) in the period between the $9^{\text {th }}$ and the $14^{\text {th }}$ of April 2020 (from https://www.data.gouv.fr/fr/reuses/carte-de-levolution-du-covid-enfrance/, https://coronavirus.data.gov.uk/\#regions, https://github.com/open-covid-19/data\#metadata). We considered the cumulated number of confirmed cases of COVID-19 per 1000 inhabitants. We calculated the tertiles of the distribution of this indicator within each country, and we generated a dummy variable for living in a region with high number of the COVID-19 cases (regions above the third tertile). 
We calculated the adjusted proportions (i.e., predicted probabilities) for the three alternative fertility plans by using multinomial models and including one by one the socio-demographic variables of our interest and controlling for gender. Because of the relatively low sample sizes, some clear trends in our data did not result in statistically significant differences. When significant results are commented, the corresponding $\mathrm{p}$-value has been added in parentheses.

\section{Results}

Just few days after this survey has been conducted, the scenario about the COVID-19 was the one described in Table 1. The country-level count of the number of positive cases gives a rough idea on how the pandemic affects countries differently. The same table reports the distribution of other indicators (previous to the pandemic) at the country-level and at the regional-level for regions with a high number of COVID-19 cases (aggregated). Across countries, Italy and Spain show the worst scenario in terms of both labour market and fertility indicators. Generally, the regions most affected by the COVID-19 are those where women and young people show (on average) better conditions in the labour market compared to the country average. For fertility indicators, only for Italy and Spain we can observe a higher fertility rate in the most affected regions compared to the country average.

The proportion of individuals who were planning in January to conceive a child during the 2020 is roughly the same across countries, but slightly higher in Italy and France $(26.6 \%$ and $27.5 \%$ respectively) than in Germany, Spain and UK (respectively 21.4\%, 21.6\% and 23.6\%). However, the consequences of the crisis seem unequal across them. Three alternative patterns appear from our data (Table 1). First, there are countries where the impact seems to be (relatively) less dramatic: in France and Germany the emergency has produced a quite high number of postponers, but a relatively small number of abandoners; more than the $30 \%$ of the plans are still ongoing. The second is observed for Spain and UK, where still-planners are about 20\% (less than in France and Germany), but most of the others are more prone to postpone than to abandon (even though in Spain the proportion of abandoners is 10 percentage points higher than in UK). Finally, in Italy the percentage of stillplanners is in between the two previous groups, but with an equally high proportion of postponers and abandoners. In particular, the prevalence of abandoners in Italy is substantially higher than in the other countries. 
Table 1. Sample distribution on fertility plans and some country and regional level indicators on the COVID-19, on young people and women employment conditions, and on fertility.

\begin{tabular}{lccccc}
\hline & Italy & Germany & France & Spain & UK \\
\hline Data from Rapporto giovani: & & & & & \\
Original sample size & 2000 & 1000 & 1000 & 1000 & 1000 \\
& & & & & \\
$\begin{array}{l}\text { Sample size of those planning to have a child in } \\
\text { January 2020 }\end{array}$ & 532 & 214 & 275 & 216 & 236 \\
& & & & & \\
\% Still planners & 25.56 & 30.70 & 32.03 & 21.17 & 23.04 \\
\% Postponers & 37.93 & 55.10 & 50.70 & 49.57 & 57.78 \\
\% Abandoners & 36.51 & 14.20 & 17.27 & 29.26 & 19.18 \\
& & & & & \\
\hline
\end{tabular}

\section{Contextual data:} Number of COVID-19 cases in mid-April 2020 (1000
inhabitants)

in the country

$\begin{array}{lllll}2.72 & 1.56 & 1.98 & 3.91 & 1.45\end{array}$

in the regions with the highest number of cases $^{1}$

$\%$ of NEET (15-24) in $2019^{2}$

in the country

in the regions with higher number of cases

$\begin{array}{lllcl}18.00 & 5.70 & 10.60 & 12.10 & 11.50 \\ 11.80 & 5.20 & 11.10 & 8.60 & 13.10\end{array}$

Female employment rate (25-34) $2019^{3}$

in the country

in the regions with higher number of cases

$\begin{array}{lllll}50.20 & 73.00 & 62.90 & 58.40 & 71.50 \\ 68.40 & 78.20 & 74.20 & 76.70 & 76.40\end{array}$

mean age at first birth $2018^{3}$

in the country

in the regions with higher number of cases

$\begin{array}{lllll}32.00 & 31.10 & 30.60 & 32.20 & 30.60 \\ 32.00 & 31.20 & 30.50 & 32.80 & 30.40\end{array}$

\section{Fertility rate $\mathbf{2 0 1 8}^{3}$}

in the country

in the regions with higher number of cases

$\begin{array}{lllll}1.29 & 1.57 & 1.88 & 1.26 & 1.68 \\ 1.40 & 1.55 & 1.74 & 1.29 & 1.64\end{array}$

\footnotetext{
Notes

${ }^{1}$ Average across regions. Regions with high number of COVID-19 cases are those in the third tertile of the regional distribution on this indicator (Italy: Valle d'Aosta, Emilia Romagna, Liguria, Lombardia, Piemonte, Trentino Alto Adige, Veneto; Germany: Baden Wuttemberg, Bavaria, North Rhine, Saarland; France: Bourgogne France Comte, Corsica, Grand Est, Hauts de France, Ile de France; Spain: Noreste, Madrid; UK: Greater London, North East, North West, Wales) Sources: https://www.data.gouv.fr/fr/reuses/carte-de-levolution-du-covid-en-france/; https://coronavirus.data.gov.uk/\#regions ; https://github.com/open-covid-19/data\#metadata

${ }^{2}$ Source: Eurostat (age: 15-24); UK Government for England (age: 16-24); Wales Government for Wales (age: 16-24)

${ }^{3}$ Source: Eurostat
} 
Fertility plans have not changed in the same way across age groups both within and between countries (Figure 1). A common cross-country tendency is represented by the increasing proportion of stillplanners with age, which is higher among individuals aged 25-29 and 30-34, as compared to their younger counterpart (18-24).

Figure 1. Adjusted proportions of the three fertility plans in the three age classes, by country (multinomial models, controlling for gender).
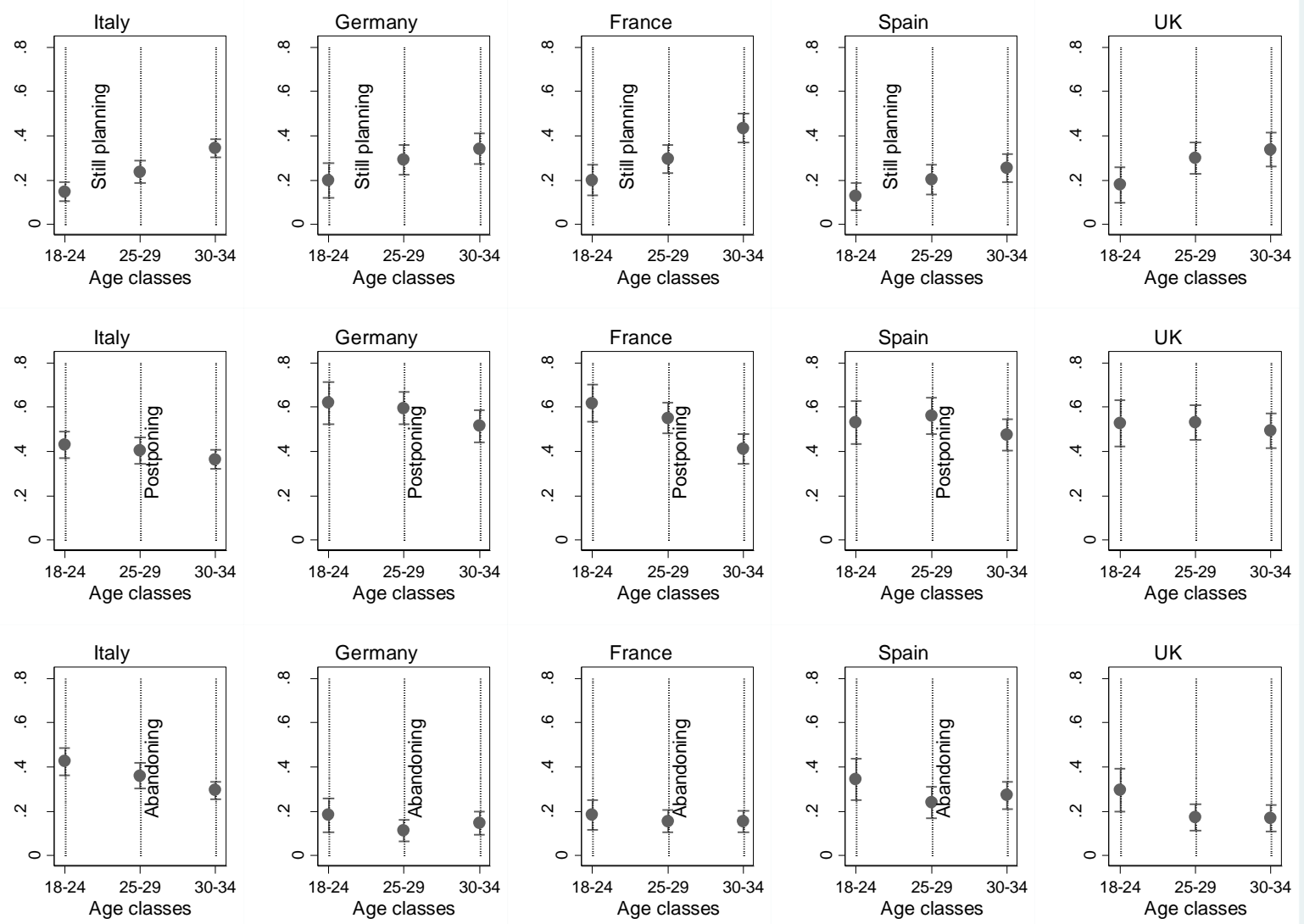

Given that a high proportion of individuals aged 18-24 in our sample is still enrolled in school/university, we restricted the sample to individuals aged 25-34 to examine the role of education. More specifically, we explored whether having a higher education might be protective with respect to the pre-crisis fertility plans (Figure 2). Higher education might be associated with a higher socioeconomic status: this might reduce the uncertainty derived by the economic crisis. A positive tendency appears only for Italy (p-value: 0.045 ) and UK, where having a tertiary degree is associated with a higher prevalence of still-planners, while a lower prevalence of abandoners (only in the Italian case). In Spain, having a tertiary education is associated with a higher proportion of postponers compared to those who do not have an academic degree, while in Germany (p-value: 0.024) and France with a slightly higher proportion abandoners. Across countries, it seems that having a tertiary 
education tends to level off the probability of abandoning the original fertility plans, while among lower educated great cross-country differences exist.

Figure 2. Adjusted proportions of the three fertility plans for those having or not having a tertiary degree, by country (multinomial models, controlling for gender); age 25-34 only.
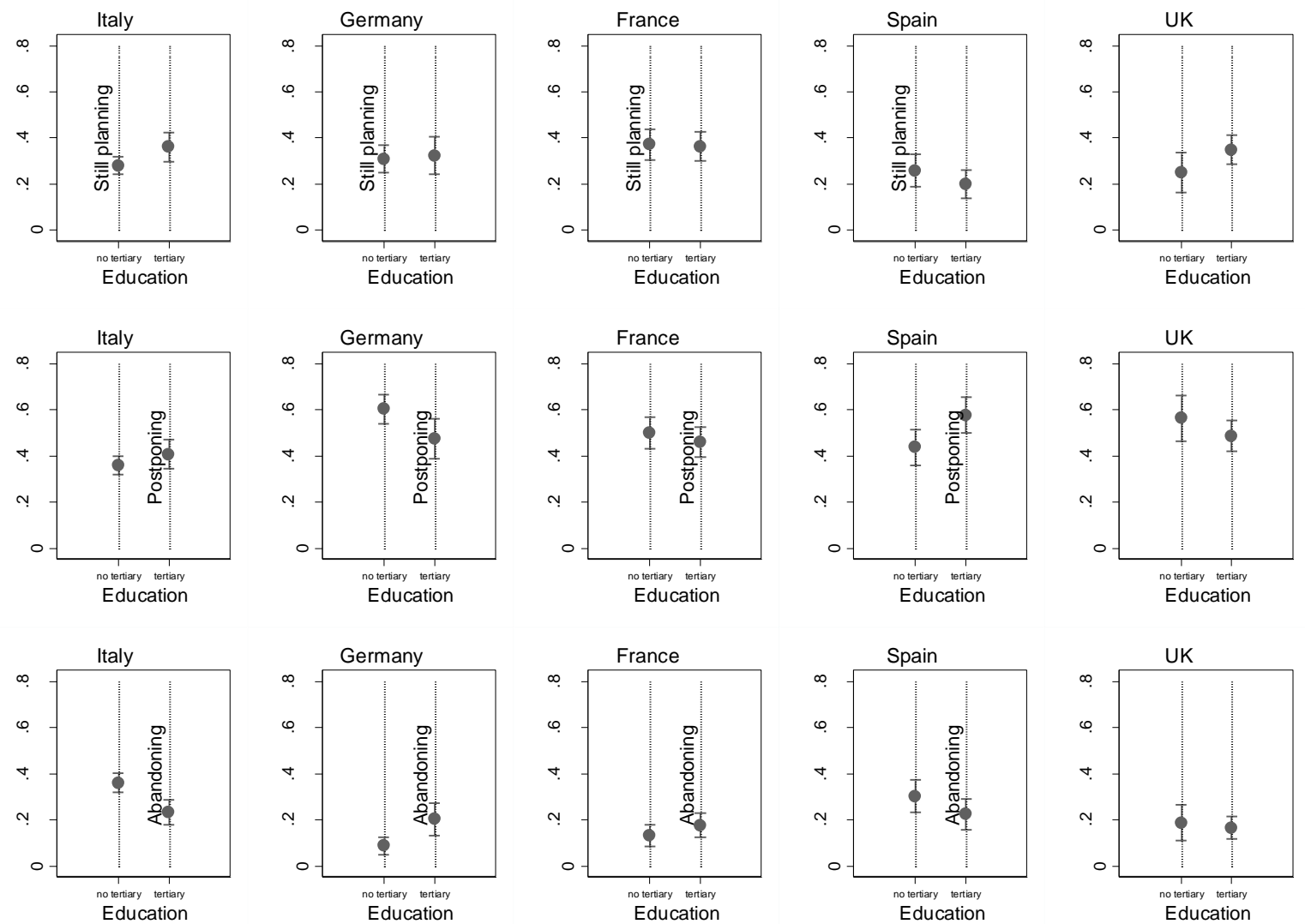

The more individuals expect their income in the future to be insecure due to the current economic crisis, the greater might be the probability that their fertility plans will change. This tendency appears in our data for UK (p-value: 0.063). In these cases, in fact, those perceiving their personal income as at risk show a lower propensity to be still planning a child, a higher proportion of postponers in Spain and of abandoners in Italy and UK. 
Figure 3. Adjusted proportions of the three fertility plans according to the expected effect of the crisis on the personal income, by country (multinomial models on respondents, controlling for gender); age 25-34 only.
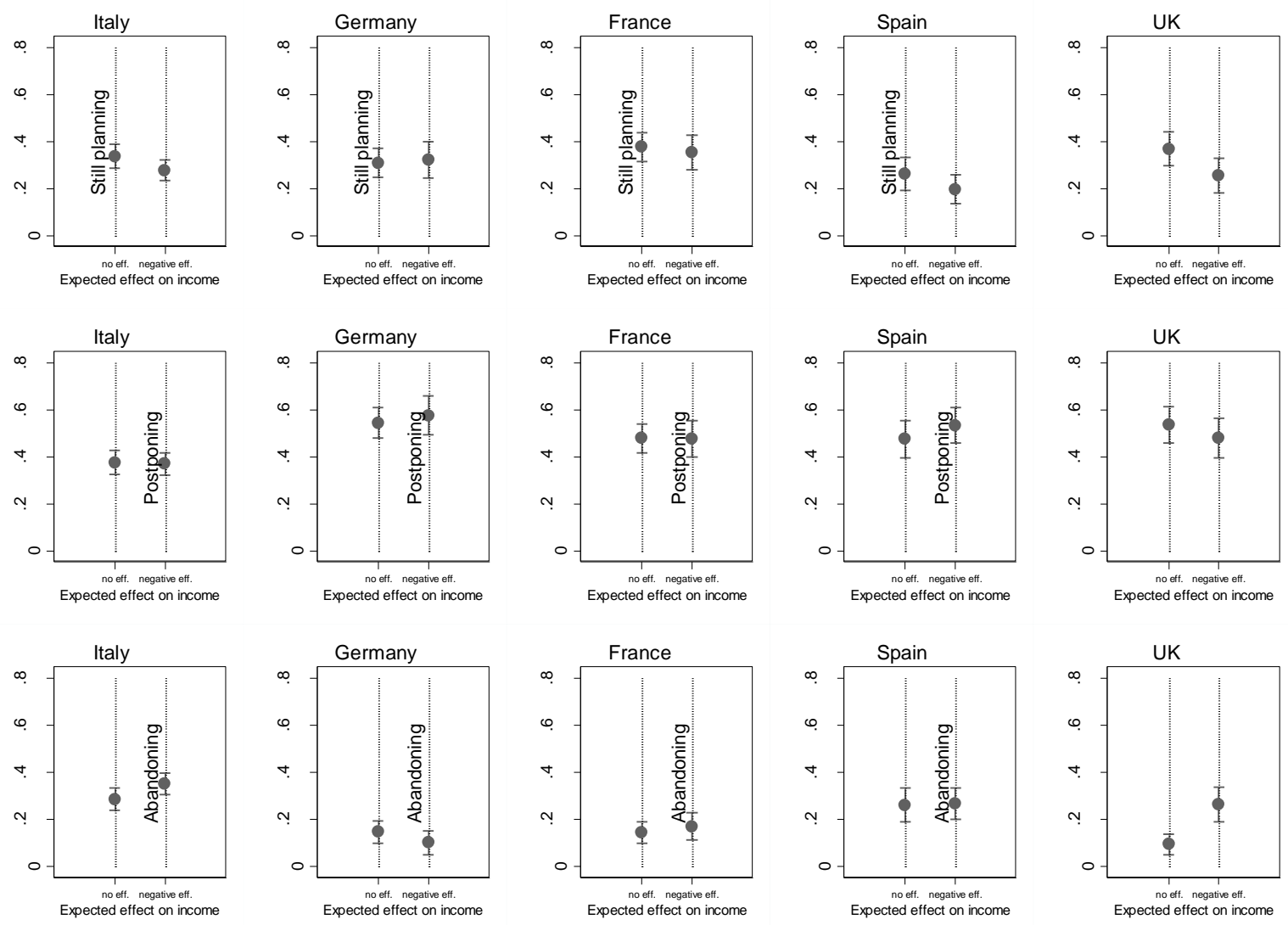

Finally, those living in regions characterized by high diffusion of the COVID-19 seems to change their fertility plans only in Germany (p-value: 0.076), France and UK (p-value: 0.092). In these countries, in fact, in "red" regions as compared to the others, we observe a lower proportion of still planners and in Germany a higher proportion of abandoners, while this is not the case in Spain and Italy, where the pattern seems to be reversed (Figure 4). 
Figure 4. Adjusted proportions of the three fertility plans according to the regional level of spread of the COVID19, by country (multinomial models on respondents, controlling for gender); age 25-34 only.
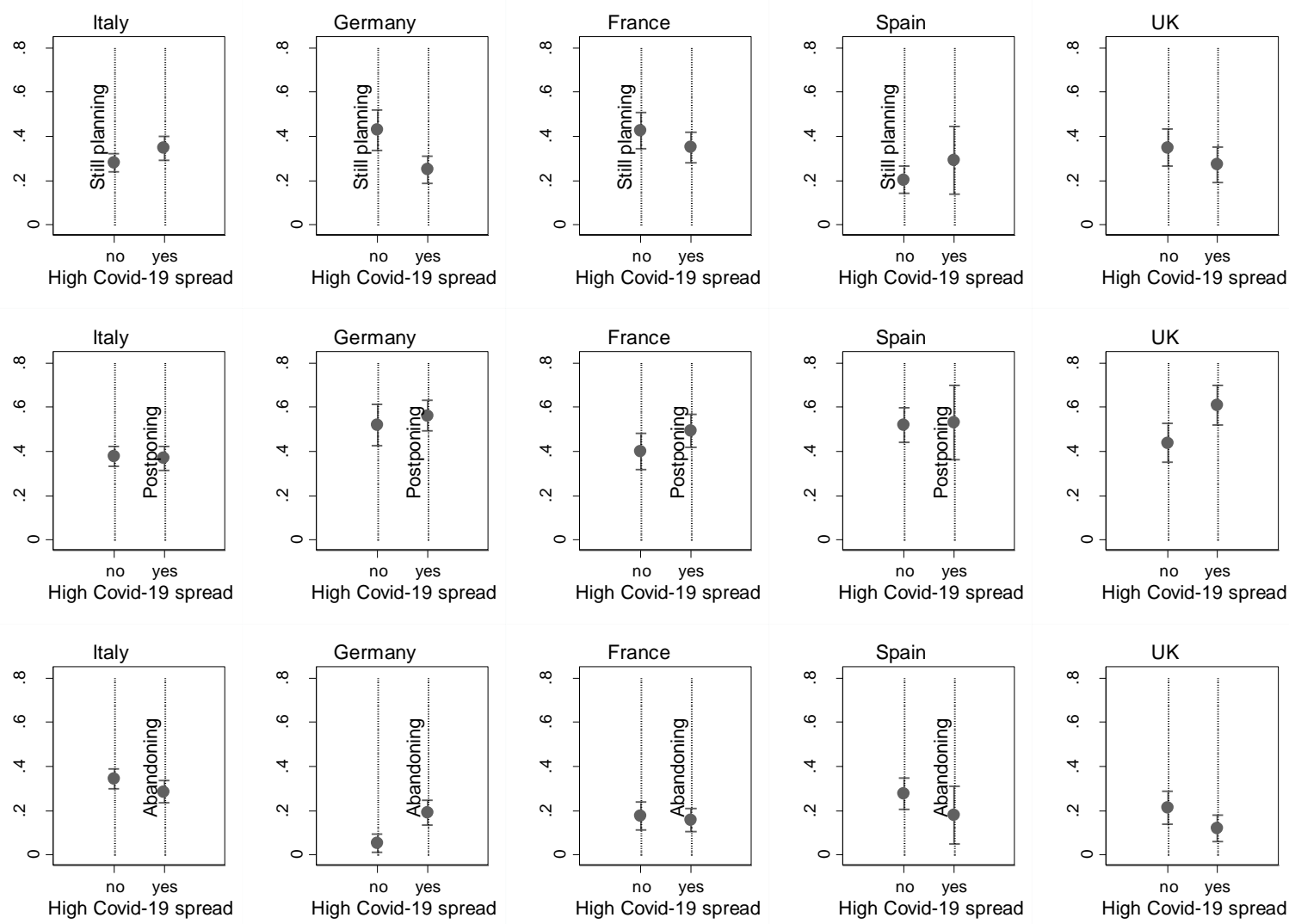

\section{Discussion}

Our study provides evidence of how fertility plans of young people in five European countries have changed during the COVID-19 pandemic. Differences arise between and within countries according to the socio-demographic characteristics of the individuals. In countries where the previous economic and labour market situation was more positive (i.e. Germany and France) the proportion of those abandoning the fertility plans for 2020 is much lower than in the other countries; these countries, instead, show the highest proportion of people still planning a child for the 2020. On the contrary, in Southern European countries, and more dramatically in Italy (the first country affected by the pandemic and with a more strict lockdown), people are more often abandoning - and not simply postponing - their pre-crisis fertility plans.

The only recurrent result within countries is the "protective" effect of age in maintaining the original fertility plans. A possible explanations can be the fact that those in their 30s - and especially women - are more prone to preserve their pre-crisis fertility plans at least at the beginning of the crisis 
(Sobotka et al. 2011), which seems to be consistent with the lower tendency to postpone the decision among those who are 30-34 compared to the other two groups. In Italy also the tendency to abandon is lower for the oldest, while in the other countries there are no differences with the group 25-29. This very unique path might be due to higher mother's age at first birth in Italy compared to the other countries; thus, among those who are 30-34, childlessness may be more prevalent in Italy than in other countries (Sobotka and Beaujouan 2018). As shown by previous research, at least in Italy the Great Recession did not change the propensity to have the first child for women in their last years of the reproductive period (Caltabiano et al. 2017), while at younger ages (below 30) fertility has been more affected (Goldstein et al. 2013).

The economic uncertainty derived by the crisis is not instead clearly associated with a higher probability to abandon or postpone fertility plans within countries, except in the case of UK. In this case, in fact, those perceiving higher income related risk from this crisis have the same probability to abandon their original fertility plans as in Spain and Italy. The fact that UK is the only country in the sample with a liberal welfare state - i.e. where policy measures to protect the personal income are less developed than in other types of welfare states - might explain why expectations on personal income are so relevant in determining fertility decision.

Even the prevalence of COVID-19 cases in the region does not suggest a consistent path of association with the change in fertility expectation across countries. Only in Germany, France and UK, the "red" regions show a higher prevalence of abandoners or postponers. In Italy and Spain for example, the probability to abandon is lower in the regions most affected by the pandemic. In these cases, at least, the most affected regions are also among the most economically performant of the country, and those with a fertility rate higher than the country average.

Our results suggest that the possible effect of the COVID-19 epidemic and the subsequent economic crisis cannot be merely interpreted under the same mechanisms in all European countries. Previous economic and demographic conditions (as arguably the type of welfare state), at least in part inherited by the Great Recession, seem to shape the fertility plans of the young population across countries. 


\section{References}

Adsera, A. (2004). Changing fertility rates in developed countries. The impact of labor market institutions. Journal of Population Economics, 17(1), 17-43.

Adsera, A. (2011). Where are the babies? Labor market conditions and fertility in Europe. European Journal of Population/Revue européenne de Démographie, 27(1), 1-32.

Bordone V., Arpino B., and Aassve A. (2017) Patterns of grandparental childcare across Europe: the role of the policy context and working mothers' need. Ageing \& Society, 37(4), 845-873.

Caltabiano, M., Comolli, C. L., \& Rosina, A. (2017). The effect of the Great Recession on permanent childlessness in Italy. Demographic Research, 37, 635-668

Goldstein, J. R., Kreyenfeld, M., Jasilioniene, A., \& Orsal, D. K. (2013). Fertility reactions to the "Great Recession" in Europe: Recent evidence from order-specific data. Demographic Research, 29(4), 85-104.

Kreyenfeld, M. (2016). Economic uncertainty and fertility. In Social Demography Forschung an der Schnittstelle von Soziologie und Demografie (pp. 59-80). Springer VS, Wiesbaden.

Matysiak, A., Vignoli, D., \& Sobotka, T. (2018). The Great Recession and fertility in Europe: A subnational analysis (No. 02/2018). Vienna Institute of Demography Working Papers.

Matysiak, A., Sobotka, T., \& Vignoli, D. (2018). The Great Recession on fertility in Europe: A subnational analysis. (Vienna Institute of Demography Working Papers 02/2018). Retrieved from https://www.econstor.eu/bitstream/10419/184849/1/WP2018_02.pdf

Price, D., Ribe, E., Di Gessa, G., \& Glaser, K. (2018). Grandparental childcare: a reconceptualisation of family policy regimes. In: Timonen, V. (Eds) Grandparenting practices around the world. Policy Press: Bristol, UK, pp. 43-62.

Sobotka, T., Skirbekk, V., \& Philipov, D. (2011). Economic recession and fertility in the developed world. Population and development review, 37(2), 267-306. 
Sobotka, T., \& Beaujouan, É. (2018). Late motherhood in low-fertility countries: Reproductive intentions, trends and consequences. In Preventing age related fertility loss (pp. 11-29). Springer, Cham.

Vignoli, D., Tocchioni, V., \& Mattei, A. (2019). The impact of job uncertainty on first-birth postponement. Advances in Life Course Research, 100308. 